\title{
Benefit Evaluation of Photovoltaic Power Generation Project Based on Fuzzy Comprehensive Evaluation Model
}

\author{
Yaru Han ${ }^{1, a}$, Shuyu Dai ${ }^{1, b^{*}}$ and Dongxiao $\mathrm{Niu}^{1, \mathrm{c}}$ \\ ${ }^{1}$ School of Economics and Management, North China Electric Power University, Beijing, China

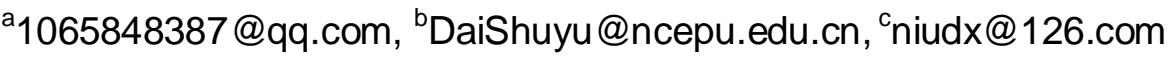 \\ * the corresponding author
}

Keyword: Photovoltaic power generation; Economic benefits; Social benefits; Comprehensive evaluation

\begin{abstract}
The research on the evaluation method of photovoltaic power generation project will help to find and correct the problems in the process of project evaluation, and promote the healthy development of photovoltaic power generation industry in china. This paper takes a photovoltaic power generation project in a western province of China as an example. Considering the economic and social benefits, the comprehensive benefit evaluation index system is established, and the fuzzy comprehensive evaluation model is used to evaluate benefits of the project.
\end{abstract}

\section{Introduction}

With the world's energy shortage and the deterioration of the ecological environment are becoming more and more prominent, the importance and urgency of the development and utilization of renewable energy are increasingly highlighted. In renewable energy, solar energy is being applied more and more in the world with so many advantages, such as environmentally friendly, large reserves, wide distribution, low cost and so on. The global solar power industry is in a period of vigorous development. During the "12th Five-Year" period, China's photovoltaic technology has made remarkable progress, and the market scale has also expanded rapidly. According to the status of solar energy resources in China and the necessity of photovoltaic power generation development, China's photovoltaic power generation construction has a bright future. In the next period of time, the construction of photovoltaic power generation projects in China will maintain a good momentum.

Because the photovoltaic power generation industry is in its growth stage, there are some problems in the comprehensive evaluation of the project inevitably. For example: the project data is not accurate, the evaluation indexes are not unified and reasonable etc. The research on the evaluation method of photovoltaic power generation project will help to find and correct the problems in the process of project evaluation, and promote the healthy development of photovoltaic power generation industry in china.

\section{Comprehensive Benefit Evaluation Index System}

Taking a province in western China as an example, considering the economic and social benefits of photovoltaic power generation project, this paper makes a comprehensive evaluation of the two aspects of benefits. By referring to a large amount of literature, combined with the actual situation in the region and relevant industrial policies, a large number of indexes related to economic and social benefits were screened by fuzzy threshold method.

Comprehensive benefit evaluation index system is constructed, as is shown below: 


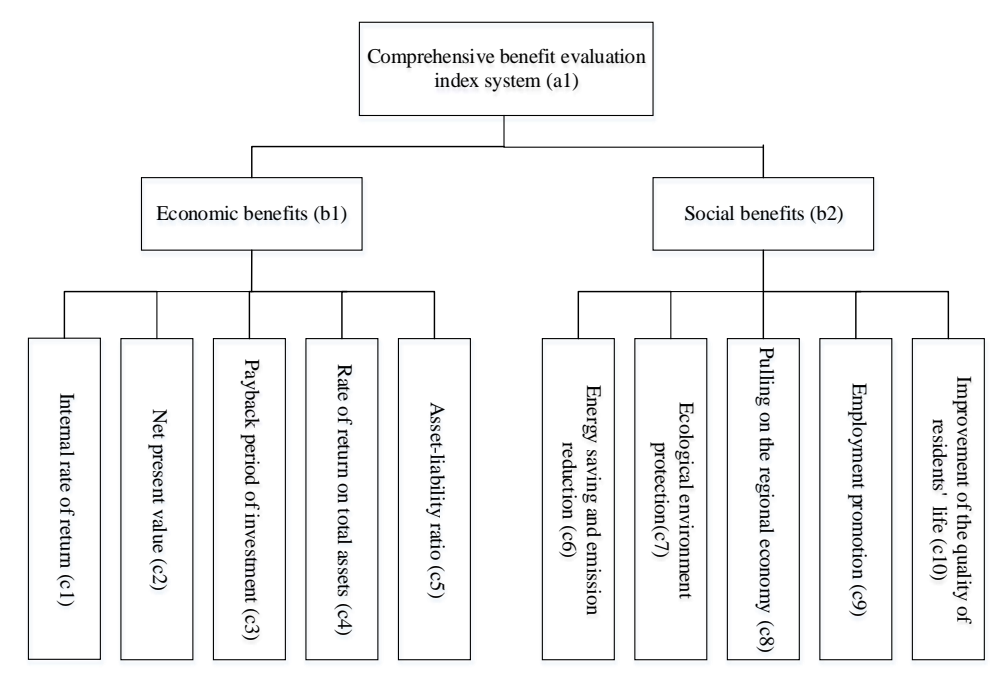

Figure 1. Comprehensive benefit evaluation index system

Economic benefits indexes

Internal rate of return(IRR)

The internal rate of return refers to the discount rate, which is also called the expected rate of return, when the sum of the present value of net cash flow at each unit point is 0 during the life of the project. It's calculated as follows:

$$
N P V(I R R)=\sum_{t=0}^{n}(C I-C O) t(1+I R R)^{-t}=0
$$

The greater the internal rate of return is, the better the economic benefit is. It is a positive index.

Net present value(NPV)

Net present value is the cumulative value of the present value of the net cash flows which generate every year over the life of the project and are converted to the same time point (generally for the early stage of project construction) at a constant discount rate (such as the industry basic rate of return). It's calculated as follows:

$$
N P V=\sum_{t=0}^{n}(C I-C O) t\left(1+i_{0}\right)^{-t}
$$

In the formula, $C I$ means cash inflows, $C O$ means cash outflows, $(C I-C O){ }^{t}$ means net cash flows in year $\mathrm{t}, i_{0}$ means the basic rate of return。The greater the net present value is, the better the economic benefit is. It is a positive index.

Payback period of investment

The payback period of investment refers to the time when the cumulative net cash flow changes from the negative number to the positive number or to zero during the life of project. The shorter the payback period, the faster the recovery rate of investment, the stronger the profitability of the project and the ability to resist risks. It is a negative index.

Rate of return on total assets

The rate of return on total assets is the ratio of the total remunerations obtained from the project to the average total assets. The utilization efficiency and profitability of assets (that is, inputs and outputs) can be reflected by this index. If the rate of return on total assets is greater than the market interest rate, then the project assets have strong ability to realize profits. It is also a positive index.

Asset-liability ratio

Asset-liability ratio is the ratio of total liabilities to total assets, which reflects the ability of the project's total assets to repay the total liabilities. Generally, the reasonable asset-liability ratio recognized by the industry should be no more than $50 \%$. Because with the increase of asset-liability ratio, the 
proportion of the project's own funds becomes smaller, the proportion of loans becomes larger, and the financial risk of the project will increase accordingly. It is an interval index.

Social benefits indexes

Energy saving and emission reduction

Using photovoltaic power generation instead of a part of traditional fossil energy generation can save non-renewable energy. It can also reduce carbon emissions and pollutant emissions, and contribute to the realization of energy saving and emission reduction targets in china.

Ecological environment protection

As a kind of clean energy, solar energy will not produce "three wastes" such as waste gas, waste water and waste residue like the traditional fossil energy, so as to prevent the ecological environment from further destruction.

Pulling on the regional economy

With the implementation of photovoltaic poverty alleviation policies, the investment scale of PV industry is getting larger and larger, and the government subsidies for PV projects are also increasing, which will promote the gathering of relevant local industries and the development of regional economy.

Employment promotion

The photovoltaic power generation project needs a large number of workers during the construction period. After the project is completed and put into operation, it also needs a lot of managers. This can create a large number of employment opportunities for local residents so as to increase the income of residents.

Improvement of the quality of residents' life

Photovoltaic power generation is helpful to improve the local ecological environment while solving local power supply and electricity consumption problems. All of these will help improve the material living standards of local residents, improve the quality of residents' life and promote the process of urbanization.

\section{Model Construction Based on Fuzzy Comprehensive Evaluation Theory}

In this paper, the weights of evaluation indexes are determined by AHP. The weights of economic benefit indexes are shown in Table 1:

Table 1 The weights of economic benefit indexes

\begin{tabular}{ccccccc}
\hline $\begin{array}{c}\text { Economic benefit } \\
\text { indexes }\end{array}$ & $\mathrm{c} 1$ & $\mathrm{c} 2$ & $\mathrm{c} 3$ & $\mathrm{c} 4$ & $\mathrm{c} 5$ & $\begin{array}{c}\text { Weight } \\
W_{i}\end{array}$ \\
\hline $\mathrm{c} 1$ & 1 & 2 & 6 & 5 & 3 & 0.43 \\
$\mathrm{c} 2$ & $1 / 2$ & 1 & 5 & 3 & 2 & 0.26 \\
$\mathrm{c} 3$ & $1 / 6$ & $1 / 5$ & 1 & $1 / 3$ & $1 / 5$ & 0.04 \\
$\mathrm{c} 4$ & $1 / 5$ & $1 / 3$ & 3 & 1 & $1 / 3$ & 0.09 \\
$\mathrm{c5}$ & $1 / 3$ & $1 / 2$ & 5 & 3 & 1 & 0.18 \\
\hline
\end{tabular}

The maximum characteristic root of judgment matrix $\lambda_{\max }=5.1641, C I=0.0410, R I=1.12$, the random consistency ratio $C R=0.0366<0.10$, the weights of evaluation indexes passed the consistency test.

The weights of social benefit index are shown in Table 2:

Table 2 The weights of social benefit indexes

\begin{tabular}{ccccccc}
\hline $\begin{array}{c}\text { Social benefit } \\
\text { indexes }\end{array}$ & $\mathrm{c} 6$ & $\mathrm{c} 7$ & $\mathrm{c} 8$ & $\mathrm{c} 9$ & $\mathrm{c} 10$ & Weight $W_{i}$ \\
\hline $\mathrm{c} 6$ & 1 & 2 & 2 & 4 & 3 & 0.38 \\
$\mathrm{c} 7$ & $1 / 2$ & 1 & 1 & 3 & 2 & 0.22 \\
$\mathrm{c} 8$ & $1 / 2$ & 1 & 1 & 2 & 2 & 0.20 \\
$\mathrm{c} 9$ & $1 / 4$ & $1 / 3$ & $1 / 2$ & 1 & $1 / 2$ & 0.08 \\
$\mathrm{c10}$ & $1 / 3$ & $1 / 2$ & $1 / 2$ & 2 & 1 & 0.12 \\
\hline
\end{tabular}


The maximum characteristic root of judgment matrix $\lambda_{\max }=5.0491, C I=0.0123, R I=1.12$, the random consistency ratio $C R=0.0110<0.10$, the weights of evaluation indexes passed the consistency test.

After determining the weights of indexes, the comprehensive benefit evaluation model of photovoltaic power generation project is constructed. In this paper, 10 comprehensive benefit evaluation indexes were selected. There are 5 economic indexes and 5 social indexes, $A_{i}$ represents the weight matrix of each index, $R_{i}$ represents fuzzy relation matrix.

Determine the factor set and comment set of comprehensive benefit evaluation. The first level set of factors is the 2 first level indexes in the index system (that is, economic and social benefits). The second level set of factors is the 10 second level indexes in the index system. The comment set $V=\left\{V_{1}, V_{2}, V_{3}, V_{4}, V_{5}\right\}=\{$ excellent, good, medium, acceptable, poor $\}$.

Determine the weight. The weights of the second level indexes are determined by AHP. The weights of the first level indexes are equal, all of which are $0.5:{ }^{A}=(0.5,0.5), A_{1}=(0.43,0.26,0.04,0.09,0.18)$, $A_{2}=(0.38,0.22,0.20,0.08,0.12)$.

According to the specific standard, the expert scoring method is adopted to judge each index according to the above comment set, the fuzzy evaluation matrix is obtained as follows, and the first level comprehensive evaluation is conducted.

$$
R_{1}=\left[\begin{array}{rrrrr}
0.25 & 0.55 & 0.1 & 0.08 & 0.02 \\
0.63 & 0.2 & 0.1 & 0.06 & 0.01 \\
0.72 & 0.25 & 0.03 & 0 & 0 \\
0.56 & 0.4 & 0.03 & 0.01 & 0 \\
0.55 & 0.35 & 0.05 & 0.04 & 0.01
\end{array}\right], R_{2}=\left[\begin{array}{rrrrr}
0.95 & 0.04 & 0.01 & 0 & 0 \\
0.86 & 0.08 & 0.06 & 0 & 0 \\
0.75 & 0.2 & 0.05 & 0 & 0 \\
0.5 & 0.3 & 0.1 & 0.06 & 0.04 \\
0.59 & 0.23 & 0.09 & 0.05 & 0.04
\end{array}\right] .
$$$$
B_{1}=A_{1} \times R_{1}=(0.45,0.40,0.08,0.06,0.01)
$$

$$
B_{2}=A_{2} \times R_{2}=(0.81,0.12,0.05,0.01,0.01)
$$

(4)Conduct the second level comprehensive evaluation and draw conclusions.

$$
\begin{aligned}
& R=\left[\begin{array}{l}
B_{1} \\
B_{2}
\end{array}\right]=\left[\begin{array}{lllll}
0.45 & 0.40 & 0.08 & 0.06 & 0.01 \\
0.81 & 0.12 & 0.05 & 0.01 & 0.01
\end{array}\right] \\
& B=A \times R=(0.63,0.26,0.06,0.03,0.01)
\end{aligned}
$$

According to the maximum membership degree principle, the evaluation result of this photovoltaic power generation project is excellent.

In economic benefit indexes, the net present value (0.63) and payback period of investment (0.72) have a higher degree of belonging to "excellent". The degree of belonging to "excellent" of rate of return on total assets and asset-liability ratio is generally acceptable. The internal rate of return's degree of belonging to "excellent" is 0.25 , the degree of belonging to "good" is 0.55 and there is room for improvement. In terms of overall economic benefits, the degree of belonging to "excellent" $(0.45)$ is general, the degree of belonging to "good" is 0.40 . This may be due to the photovoltaic power generation industry is still in the early stages of development, cost control is not mature, policy subsidies are not in place, large-scale development has not been formed.

In social benefit indexes, the project has achieved good results in three aspects: energy saving and emission reduction, ecological environment protection and pulling on the regional economy. The degree 
of belonging to "excellent" are $0.95,0.86$ and 0.75 respectively. The degree of belonging to "excellent" of employment promotion and improvement of the quality of residents' life are 0.5 and 0.59 respectively, which are generally acceptable. In terms of overall social benefits, the degree of belonging to "excellent" is 0.81 . This shows that the project has a good contribution to the local social development.

\section{Summary}

The region in western China has strong solar radiation, sufficient illumination and relatively low development cost. It is advantageous for the development of photovoltaic power generation industry. Based on the latest research status of photovoltaic power generation projects at home and abroad, relevant domestic policies and project conditions, the comprehensive benefit evaluation index system and the model based on fuzzy comprehensive evaluation theory are constructed to evaluate the comprehensive benefits of photovoltaic power generation projects in this area. Photovoltaic power generation industry can not only bring economic benefits to enterprises, but also promote regional environmental protection and economic development. The evaluation index system and evaluation method constructed in this paper can provide reference for the evaluation of such projects.

\section{References}

[1] X. Zhang: Research on the Comprehensive Benefit Evaluation of Distributed Photovoltaic Power Generation Project (MS., North China Electric Power University, China 2014), p.19. (In Chinese)

[2] J.L. Tian: Research on Comprehensive Benefit Evaluation of Photovoltaic Generation under Low Carbon Economy (MS., North China Electric Power University, China 2013), p.16. (In Chinese)

[3] H. Zhang: Study on the Feasibility Comprehensive Evaluation of Tuoketai Photovoltaic Power Generation Project (MS., North China Electric Power University, China 2014), p.13. (In Chinese)

[4] Y. Wang: Comprehensive Evaluation of Large Distributed Photovoltaic Generation Project (MS., North China Electric Power University, China 2015), p.25. (In Chinese)

[5] F.P. Jiang: Research on Comprehensive Benefit Evaluation of Photovoltaic Power Generation Project (MS., Hubei University of Technology, China 2016), p.21. (In Chinese)

[6] L. Yang, L. Tan and Y. Liu: Study on Risk Assessment of Photovoltaic Power Generation Project Based on Fuzzy Comprehensive Evaluation, Vol. 29 (2014) No.5, p.427. (In Chinese)

[7] W.S. Gu: Technical and Economic Analysis and Comprehensive Evaluation of Anbai Landscape Belt Photovoltaic Power Generation Project (MS., North China Electric Power University, China 2013), p.41. (In Chinese)

[8] J.Y. Zhang: Research on Photovoltaic Power Generation Project Investment Decision of M Company in Heilongjiang Province (MS., China University of Geosciences, China 2014), p.44. (In Chinese)

[9] M. Cheng, S.Z. Zhao, L.J. Wu, C.S. Hu and H. Xu: Comprehensive Evaluation of Urban Photovoltaic Power Generation Project Based on AHP - TOPSIS, Vol. 49 (2016) No.10, p.173. (In Chinese)

[10] W.J. Zhao: Economic Benefit Analysis of Distributed Photovoltaic Power Generation Project in Yunnan Province (MS., Yunnan University, China 2016), p.10. (In Chinese) 